\title{
Exogenous abscisic acid inhibits the water-loss of postharvest romaine lettuce during storage by inducing stomatal closure
}

\author{
Shuchun $\mathrm{LIU}^{1}$, Ming YANG ${ }^{1}$, Huijie $\mathrm{ZHAO}^{1}$, Hua $\mathrm{LI}^{1}$, Biao $\mathrm{SUO}^{1}$, Yuexia WANG ${ }^{1 *}$
}

\begin{abstract}
Postharvest lettuce often lose water, thus affecting both its market value and consumer acceptance. However, the mechanism of the water-loss is still waiting well exploration. The aim of the present study was to investigate the effect of a foliar application of $\mathrm{ABA}$ on the fresh weight-loss and the chlorophyll content of postharvest lettuce as well as its association with the regulation of stomata. The present data demonstrated that exogenously application of $\mathrm{ABA}$, in a concentration range of 0 to $100 \mu \mathrm{M}$, significantly lowered the fresh weight-loss of postharvest lettuce. ABA also delayed chlorophyll reduction during ambient storage, but this protective effect was ABA concentration-dependent. Among the tested ABA concentrations, $50 \mu \mathrm{M}$ or lower ABA produced an inhibition effect on chlorophyll degradation in postharvest lettuce leaves. The results demonstrated that the exogenous ABA treatment can obviously reduce the transpiration rate of lettuce leaves by promoting the stomatal closure of postharvest lettuce, therefore eventually delay fresh weight-loss. The present study primarily showed that the application of exogenous ABA, which originated from a naturally-produced phytohormone, has a great potential in retaining the freshness of postharvest lettuce that is stored in an ambient condition, although possible practical application still need to be further evaluated.
\end{abstract}

Keywords: lettuce; postharvest; abscisic acid; water-loss; stomatal closure.

Practical Application: The effect of a foliar application of ABA on postharvest lettuce was investigated. The results demonstrated that the ABA, which originated from a naturally-produced phytohormone, can obviously reduce the transpiration rate of lettuce leaves by promoting the stomatal closure of postharvest lettuce, therefore eventually delay fresh weight-loss and chlorophyll reduction during ambient storage. The strategy could potentially be used as an alternative for lettuce producer and retailer to effectively retain the fresh of postharvest lettuce products.

\section{Introduction}

Romaine lettuce (Lactuca sativa L.), rich in dietary fiber and vitamin $\mathrm{C}$, is a widely popular choice among consumers because of its freshness, nutritional value, and convenience (Kim et al., 2014). However, in contrast from the plant grows in the fields, romaine lettuce can only use the remaining internal water; therefore, it will continue to lose water during postharvest transportation and storage, especially at ambient conditions (Xanthopoulos et al., 2014). Furthermore, the water loss of postharvest vegetables is a severe problem because it leads to leaf wilting and fresh weight-loss, which will then impact the vegetables' appearance and storage time (Mahajan et al., 2008). Moreover, vegetables and fruits will be senescent soon after harvest; the primary observable attribute is a decreased chlorophyll content, which is significant because the amount of remaining chlorophyll is considered to be a means of measuring the quality of green vegetables (Sweeney \& Martin, 1961).

Transpiration is considered to be the main stimulant of the weight-loss and quality deterioration of leafy vegetables (Hung et al., 2011). In higher plants, the photosynthesis and transpiration rates of leaves have been shown to be associated with regulating the openings of stomata (Barbieri et al., 2012). A stoma is surrounded by two guard cells, and a change in the turgor pressure of guard cells triggers stomatal opening (Hetherington \& Woodward, 2003). This change in turgor pressure is a result of the exchange of water in and out of the guard cells (Kollist et al., 2014).

In previous studies, different kinds of methods have been developed in order to retain the freshness of fresh-cut lettuce or other vegetable (Del Nobile et al., 2008; Kasim \& Kasim, 2015; Martín-Diana et al., 2008; Zhang et al., 2006). Plant hormone is a kind of naturally produced small molecular residues, which has been proven to be closely associated with plant development and stress resistance (Wang et al., 2014). A recent study has shown that, the application of plant hormone salicylic acid could significantly delay the pericarp browning and quality degradation of ambiently stored litchi fruit (Kumar et al., 2013). However, until now, there has not been a reported preservative method designed to retain the fresh weight of postharvest lettuce via the alleviation of transpiration through specifically closing the stomata.

Abscisic acid (ABA) is a well-known plant hormone that plays a vital role in plant growth and development, such as seed dormancy and germination (Song et al., 2011). In addition, $\mathrm{ABA}$ is also considered the major factor of stomatal movement 
(Dodd, 2003). It has already been used for retaining the freshness of postharvest flowers, and it has been proposed to be related to moisture adjustment and stomatal closure (Barthe et al., 1991). Moreover, an ABA-deficient mutant assay has demonstrated the important role of $\mathrm{ABA}$ in the fresh keeping of postharvest citrus fruit (Alférez et al., 2005). However, there is no report about the use of an exogenous application of ABA in the freshness of postharvest lettuces.

The present study is aimed at studying the effect of the application of exogenous $\mathrm{ABA}$ on postharvest lettuce during ambient storage. The regulation mechanism was also discussed from the aspect of stomatal closure. The results will not only be helpful for the understanding of fresh-loss mechanism of postharvest lettuce, but also be applicable for designing a novel means of ensuring quality and prolonging the shelf life of postharvest lettuce.

\section{Materials and methods}

\subsection{Sample preparation}

Romaine lettuce (Lactuca sativa L.) was purchased from a local farm and transported to the laboratory in less than two hours. The plants were selected for uniformity of color and size. The selected lettuce was roughly washed with cold tap water $\left(5^{\circ} \mathrm{C} \pm 2\right)$ in order to eliminate any soil. Then, the outer leaves and the core of the washed lettuce were removed, and the remaining leaves were used for the experiment. Prior to applying the ABA treatment, all of the leaves were again washed in cold tap water $\left(5^{\circ} \mathrm{C} \pm 2\right)$ before having their surfaces sterilized by immersion in a $0.2 \%(\mathrm{v} / \mathrm{v}) \mathrm{NaClO}$ solution (pH 6.5 adjusted with citric acid) for $30 \mathrm{~s}$. The excess of water on leave's surface was removed by a manual salad spinner (Gelin Plastic Co. Ltd, Taizhou, China) for $30 \mathrm{~s}$. In total, there were five ABA treatments, comprised of $0,10,20,50$, and $100 \mu \mathrm{mol} / \mathrm{L}$, respectively. The leaves were dipped for $5 \mathrm{~min}$ in the solutions and then air dried for $30 \mathrm{~min}$. Then, one piece of leaf for each sample was placed in a $25 \times 30 \mathrm{~cm}$ polyethylene packet that had $2 \%$ ventilation. Thereafter, leaves were stored in ambient storage conditions (temperature $25 \pm 2{ }^{\circ} \mathrm{C}, \mathrm{RH} 85 \pm 5 \%$ ) under a 14-hr photoperiod and light of $80 \mu \mathrm{mol} \mathrm{m}^{-2} \mathrm{sec}^{-1}$ (Fan et al., 1997). The following sections detail the parameters that were analyzed $0,1,2,3,4$, and $5 \mathrm{~d}$ of storage.

\subsection{Determination of fresh weight-loss}

Fresh weight-loss was determined as described by Rizzo \& Muratore (2009). All samples were weighed by a Chyo Balance MK-500C $( \pm 0.01 \mathrm{~g})$ at the beginning as well as immediately following each of the storage times. The difference between the two values was considered to be fresh weight-loss. For each measurement, 20 leaves corresponding to each treatment were used, and the experiment was performed in triplicate.

\subsection{Determination of chlorophyll content}

To evaluate the chlorophyll content, a portable chlorophyll meter (SPAD-502, Minolta, China) was used directly (Torres et al., 2005). In this experiment, at least 20 leaves were measured, and more than five points were chosen on each leaf. Every experiment was measured three times, and the mean values were obtained.

\subsection{Determination of transpiration rate}

The transpiration rate was measured according to Xanthopoulos et al. (2014) with some modifications. For one leaf from each treatment, a $5 \times 5 \mathrm{~cm}$ square was cut and weighted immediately; the weight was recorded as well as the starting time, and then it was put back in the processing environment. After 3-5 minutes, it was weighed again, and the weight was recorded. The transpiration rate was calculated according to the following equation: $\mathrm{TR}=(\mathrm{Mi}-\mathrm{M}) / \mathrm{A} / \mathrm{t}$, where $\mathrm{TR}$ is the transpiration rate $\left(\mathrm{mg} \mathrm{m}^{-2} \mathrm{~s}^{-1}\right)$, Mi is the initial weight $(\mathrm{g}), \mathrm{M}$ is the weight of the lettuce leaf $(\mathrm{g})$ at time $\mathrm{t}(\mathrm{min})$, and $\mathrm{A}$ is the leaf area $\left(\mathrm{m}^{2}\right)$.

\subsection{Stomatal treatment and measurement}

In order to study ABA's effect on the stomatal closure of postharvest lettuce, the stomata were fully opened prior to the ABA treatment. Abaxial epidermal peels were removed from the fresh lettuce leaves and floated (abaxial side down) in MES buffer [containing $10 \mathrm{mM}$ MES-KOH (pH 6.2), $30 \mathrm{mM} \mathrm{KCl}$, and $1 \mathrm{mM}$ $\left.\mathrm{CaCl}_{2}\right]$ and then incubated under white lights $\left(25 \mu \mathrm{mol} \mathrm{m}^{-2} \mathrm{~s}^{-1}\right)$ at $25^{\circ} \mathrm{C}$ for $3 \mathrm{~h}$. The peels were then treated with $\mathrm{ABA}$ for $4 \mathrm{~h}$ at the desired concentrations. The stomatal apertures in the epidermal peels were observed with a microscope (Olympus BX51, Japan) equipped with a CCD camera. In addition, the size of the stomatal apertures was measured using a digital ruler; at least 200 stomatal apertures were measured for each treatment. Each assay was repeated three times. The data were presented as mean $\pm \operatorname{SE}(n=200)$.

\subsection{Data analysis}

All experimental data were performed at the least in triplicate, and all the data were presented as the means \pm standard errors. The data were subjected to an analysis of variance (ANOVA). The probability value of $P<0.05$ was used as the criteria for significant differences.

\section{Results}

\subsection{Effect of the ABA treatment on fresh weight loss}

As shown in Figure 1, the fresh weight-loss of the postharvest lettuce continued to increase through the five days of ambient storage, and only $33 \%$ of fresh water was left if the postharvest lettuce was stored without extra treatment. Compared to the non-ABA treated control, the fresh water loss decreased $9 \%, 13 \%$, $18 \%$, and $27 \%$, when the postharvest lettuce was foliar treated by $10,20,50$, and $100 \mu \mathrm{M}$ of ABA, respectively. The results indicated that the loss of fresh weight was significantly alleviated by the application of ABA. Moreover, the alleviation effect of ABA was improved along with the increase of $A B A$ concentration.

\subsection{Effect of the ABA treatment on chlorophyll content}

As shown in Figure 2, the chlorophyll content showed a decreasing tread during the postharvest storage, although there was a slight but not obvious increase after $3 \mathrm{~d}$. Foliar application of $10 \mu \mathrm{M}$ showed a significant alleviation effect on the decrease of chlorophyll content, which was evident by a $43 \%$ higher chlorophyll content than that of control samples without ABA 


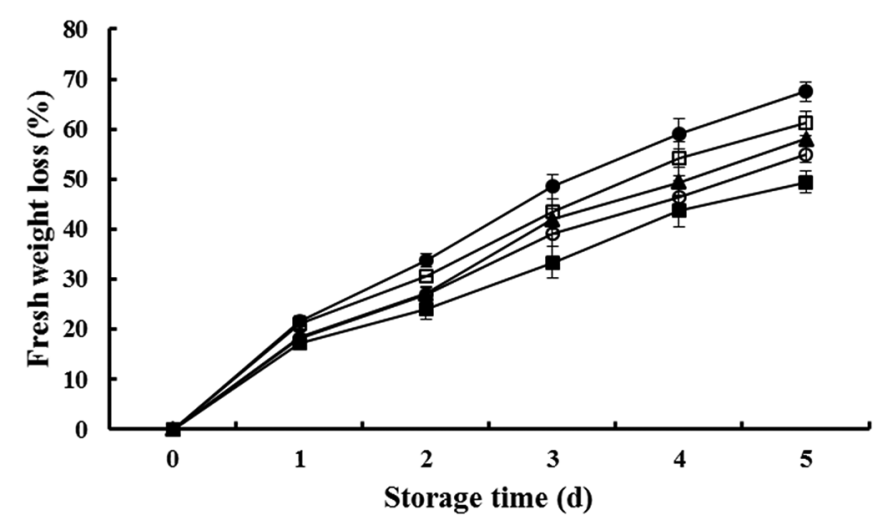

Figure 1. Effects of ABA on fresh weight-loss of postharvest lettuce during ambient storage. Each value is the mean of three replicates, and vertical bars indicate the standard errors (SE). $\bullet, 0 \mu \mathrm{M} \mathrm{ABA} ; \square, 10 \mu \mathrm{M}$ $\mathrm{ABA} ; \boldsymbol{\Delta}, 20 \mu \mathrm{M}$ ABA; ○, $50 \mu \mathrm{M}$ ABA; -, $100 \mu \mathrm{M}$ ABA.

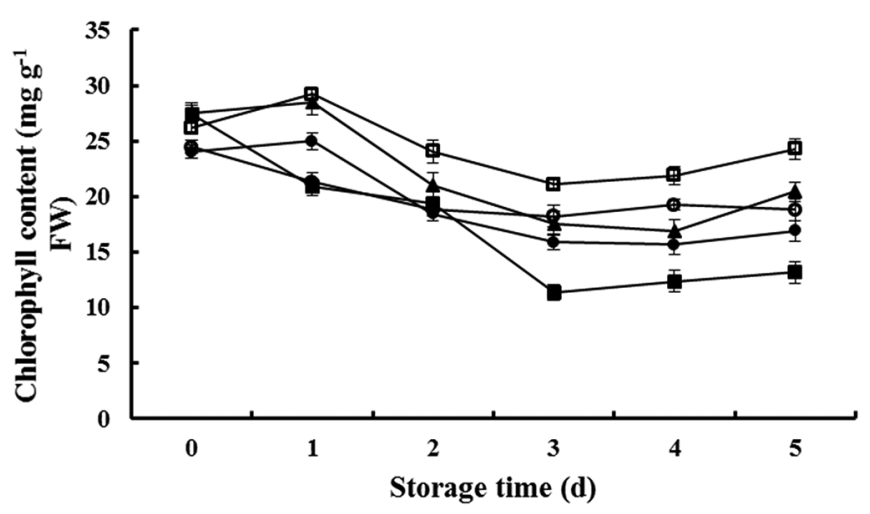

Figure 2. Effects of ABA on chlorophyll content of postharvest lettuce during ambient storage. Each value is the mean of three replicates, and vertical bars indicate the standard errors (SE). $\bullet, 0 \mu \mathrm{M} \mathrm{ABA} ; \square, 10 \mu \mathrm{M}$ ABA; $\boldsymbol{\Delta}, 20 \mu \mathrm{M}$ ABA; O, $50 \mu \mathrm{M}$ ABA; $\cdot 100 \mu \mathrm{M}$ ABA.

application after $5 \mathrm{~d}$ of storage. Interestingly, higher concentration of exogenous ABA expressed a negative effect on the alleviation of chlorophyll loss. Evenly, the $100 \mu \mathrm{M}$ treatment exhibited the lowest chlorophyll content, which decreased by 22 percentage after $5 \mathrm{~d}$ of storage.

\subsection{Effect of the ABA treatment on transpiration rate}

During storage, all the transpiration rates of postharvest lettuce showed a declining trend (Figure 3). The ABA applications could improve the decrease of transpiration rate, and the effect was enhanced by the increasing concentration of ABA. It was evident by the result that the $100 \mu \mathrm{M}$ treatment exhibited the highest decreasing effect especially during the first day of storage.

\subsection{Effect of the ABA treatment on stomatal closure}

As seen from Figure 4, when postharvest lettuce was foliar treated by $10 \mu \mathrm{M}$ of $\mathrm{ABA}$, there did not show obvious difference in stomatal aperture $(P>0.05)$, compared to non-treated control. However, when the higher concentrations of ABA were treated,

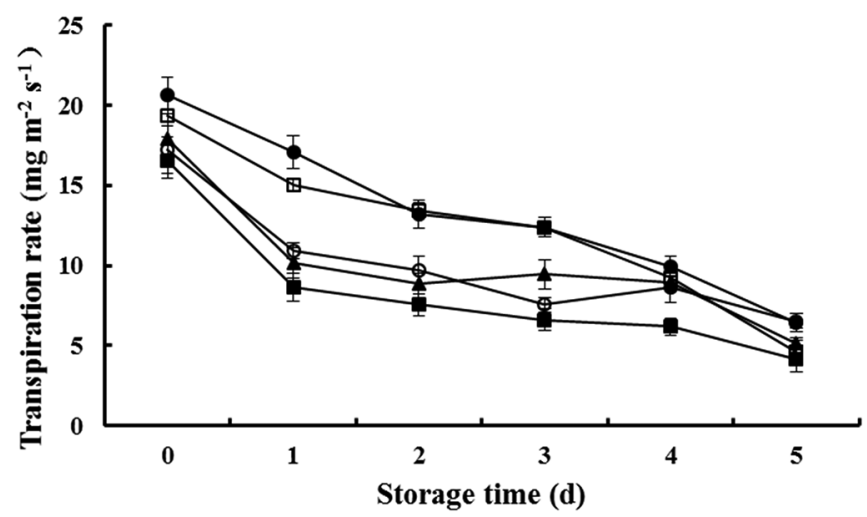

Figure 3. Effects of ABA on transpiration rate of postharvest lettuce during ambient storage. Each value is the mean of three replicates, and vertical bars indicate the standard errors (SE). $\bullet, 0 \mu \mathrm{M} \mathrm{ABA} ; \square, 10 \mu \mathrm{M}$ $\mathrm{ABA} ; \boldsymbol{\Lambda}, 20 \mu \mathrm{M} \mathrm{ABA} ; \circ, 50 \mu \mathrm{M}$ ABA; $\cdot 100 \mu \mathrm{M}$ ABA.

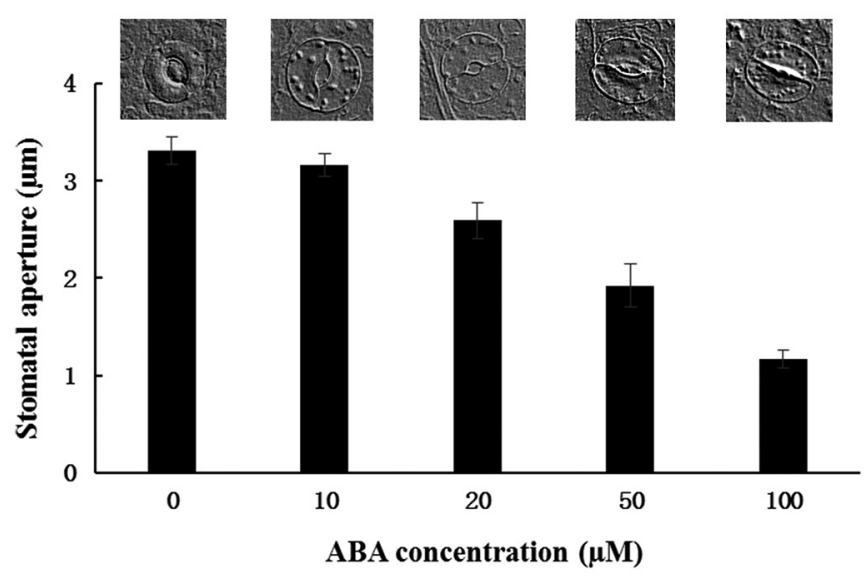

Figure 4. Effects of ABA on stomatal closure of postharvest lettuce. Each value is the mean of three replicates, and vertical bars indicate the standard errors (SE).

the stomatal aperture decreased obviously $(P<0.05)$. Moreover, the decrease of stomatal aperture was improved significantly along with the increased application of exogenous ABA. The results show that exogenous ABA can promote stomatal closure.

\section{Discussion}

Vegetables deteriorate in a progressive manner during their storage, and the cumulative effect of this deterioration renders the food undesirable to consumers (Rizzo \& Muratore, 2009). Furthermore, the less water that the lettuce loses, the less fresh weight-loss that occurs, which clearly helps maintain freshness as well as delay the shelf life of postharvest vegetables. In the present study, when postharvest lettuce was stored at ambient conditions, and the lettuce continued to lose fresh weight; however, after exogenously applying ABA, the fresh weight-loss was inhibited. The protection effect of ABA against water-loss has been proven in citrus fruit by the deficient mutant, which simultaneously exhibited a substantial increase in ethylene production, thus indicating that $\mathrm{ABA}$ negatively regulated water stress-induced ethylene biosynthesis (Alférez et al., 2005). 
In addition to the water loss, leaf yellowing (caused by the loss of a leaf's green pigmentation) can also affect the quality of postharvest vegetables as well as shorten their shelf life (Aubry et al., 2008; Chen et al., 2010). Furthermore, leaf yellowing is seen as the primary sign of chlorophyll degradation (Matile et al., 1996). In addition, according to research results that were acquired by using cut flowers (which are typically used as a model system for leaf yellowing studies) (Philosoph-Hadas et al., 1996), it is believed that leaf yellowing should be attributed to the absence of cytokinins because the major biosynthesis site is located in roots (Matile et al., 1996). Therefore, a hormone imbalance occurs, and the first visible physiological expression of this disorder is chlorophyll degradation. However, chlorophyll catabolism is tightly associated with leaf carotenoid concentration (Ferrante et al., 2004).

In the present study, the chlorophyll content in the postharvest lettuce was significantly retarded by the ABA treatment (Figure 2). The alleviation effect of ABA showed a concentration-dependent effect, and the highest chlorophyll contents were obtained when the application was $10 \mu \mathrm{M}$ of $\mathrm{ABA}$. Based on the data, it has been suggested that a low dosage of $\mathrm{ABA}$ is beneficial for retaining the freshness of postharvest vegetables, and it also has been reported that an exogenous ABA application can significantly increase the anthocyanin content in red leaf lettuce, along with the contents of chlorophyll b (Li et al., 2010).

Both fresh weight-loss and leaf yellowing are primarily related to water evaporation, which was evident from the close correlation that exists between the trends of the fresh weight-loss and the transpiration rate under the different concentrations of ABA treatments (Figures 1 and 3). Transpiration is the main cause of water-loss in postharvest vegetables; furthermore, previous studies have shown that transpiration is the key factor that limits the quality and storage time of postharvest sweet peppers (Maalekuu et al., 2003). Additionally, it has been shown to affect postharvest eggplant quality (Carlos Díaz-Pérez, 1998).

Transpiration mainly occurs through the stoma, lenticels, and epidermis. When a leaf loses excess water, the guard cells will lose water at the same time, thus leading to decreased stomatal aperture and can even result in stomatal closure. The partially closure of the stomata contributes to the decline in transpiration and the increase in efficient water use. Furthermore, ABA as an intrinsic phytohormone is known to play the central role in the reduction of water transpiration through promotion of stomatal closure (Hetherington, 2001; Kim et al., 2010). The present results also suggest that treatment with exogenous ABA can improve the partial closure of stomata, which will decrease the transpiration rate. Additionally, the stomatal conductance decreases as the ABA concentration increases (Figure 4). It has also been demonstrated that $\mathrm{ABA}$ can regulate stomatal closure in response to some outside actors; for example, ABA can inhibit stomatal opening in response to increased light intensity (Mishra et al., 2006; Roelfsema et al., 1998) and, in contrast, induce prompt stomatal closure in response to decreased light intensity (Felle et al., 2000; Hetherington \& Woodward, 2003).

\section{Conclusions}

The present study demonstrated that exogenous ABA can maintain a higher chlorophyll content, lower the fresh weight-loss, and reduce the transpiration rate by improving stomatal closure. This reveals that the application of exogenous ABA has great potential in retaining the freshness of postharvest lettuce that is stored at an ambient condition, especially. However, before it is used for the real postharvest storage condition, its usage and dosage are still waiting for further practical evaluation.

\section{Acknowledgements}

This study was financially supported by the the National 12th Five-Year Science and Technology supporting grant in China (grant no. 2015BAD16B04), the Science and Technology Department of Henan Province (grant no. 152102110055), and the Sci-tech Innovation Foundation of Henan Agricultural University.

\section{References}

Alférez, F., Sala, J. M., Sanchez-Ballesta, M. T., Mulas, M., Lafuente, M. T., \& Zacarias, L. (2005). A comparative study of the postharvest performance of an ABA-deficient mutant of oranges. Postharvest Biology and Technology, 37(3), 222-231. http://dx.doi.org/10.1016/j. postharvbio.2005.05.010.

Aubry, S., Mani, J., \& Hörtensteiner, S. (2008). Stay-green protein, defective in Mendel's green cotyledon mutant, acts independent and upstream of pheophorbide a oxygenase in the chlorophyll catabolic pathway. Plant Molecular Biology, 67(3), 243-256. http://dx.doi. org/10.1007/s11103-008-9314-8. PMid:18301989.

Barbieri, G., Vallone, S., Orsini, F., Paradiso, R., De Pascale, S., NegreZakharov, F., \& Maggio, A. (2012). Stomatal density and metabolic determinants mediate salt stress adaptation and water use efficiency in basil (Ocimum basilicum L.). Journal of Plant Physiology, 169(17), 1737-1746. http://dx.doi.org/10.1016/j.jplph.2012.07.001. PMid:22840325.

Barthe, P., Vaillant, V., \& Gudin, S. (1991). Definition of indicators of senescence in the rose: effect of the application of plant hormones. In Proceedings of the Hortifroid, V International Symposium on Postharvest Physiology of Ornamental Plants; Importance of Cold in Ornamental (SHS Acta Horticulturae, No. 298, pp. 61-68), Nice, France.

Carlos Díaz-Pérez, J. (1998). Transpiration rates in eggplant fruit as affected by fruit and calyx size. Postharvest Biology and Technology, 13(1), 45-49. http://dx.doi.org/10.1016/S0925-5214(97)00078-1.

Chen, Z., Zhu, C., Zhang, Y., Niu, D., \& Du, J. (2010). Effects of aqueous chlorine dioxide treatment on enzymatic browning and shelf-life of fresh-cut asparagus lettuce (Lactuca sativa L.). Postharvest Biology and Technology, 58(3), 232-238. http://dx.doi.org/10.1016/j. postharvbio.2010.06.004.

Del Nobile, M., Conte, A., Cannarsi, M., \& Sinigaglia, M. (2008). Use of biodegradable films for prolonging the shelf life of minimally processed lettuce. Journal of Food Engineering, 85(3), 317-325. http:// dx.doi.org/10.1016/j.jfoodeng.2007.06.040.

Dodd, I. C. (2003). Hormonal interactions and stomatal responses. Journal of Plant Growth Regulation, 22(1), 32-46. http://dx.doi. org/10.1007/s00344-003-0023-X.

Fan, L., Zheng, S., \& Wang, X. (1997). Antisense suppression of phospholipase $\mathrm{D}$ alpha retards abscisic acid- and ethylene-promoted 
senescence of postharvest Arabidopsis leaves. The Plant Cell, 9(12), 2183-2196. PMid:9437863.

Felle, H. H., Hanstein, S., Steinmeyer, R., \& Hedrich, R. (2000). Dynamics of ionic activities in the apoplast of the sub-stomatal cavity of intact Vicia faba leaves during stomatal closure evoked by ABA and darkness. The Plant Journal, 24(3), 297-304. http://dx.doi. org/10.1046/j.1365-313x.2000.00878.x. PMid:11069703.

Ferrante, A., Vernieri, P., Serra, G., \& Tognoni, F. (2004). Changes in abscisic acid during leaf yellowing of cut stock flowers. Plant Growth Regulation, 43(2), 127-134. http://dx.doi.org/10.1023/ B:GROW.0000040119.27627.b2

Hetherington, A. M. (2001). Guard cell signaling. Cell, 107(6), 711-714. http://dx.doi.org/10.1016/S0092-8674(01)00606-7. PMid:11747807.

Hetherington, A. M., \& Woodward, F. I. (2003). The role of stomata in sensing and driving environmental change. Nature, 424(6951), 901-908. http://dx.doi.org/10.1038/nature01843. PMid:12931178.

Hung, D. V., Tong, S., Tanaka, F., Yasunaga, E., Hamanaka, D., Hiruma, N., \& Uchino, T. (2011). Controlling the weight loss of fresh produce during postharvest storage under a nano-size mist environment. Journal of Food Engineering, 106(4), 325-330. http:// dx.doi.org/10.1016/j.jfoodeng.2011.05.027.

Kasim, R., \& Kasim, M. U. (2015). Biochemical changes and color properties of fresh-cut green bean (Phaseolus vulgaris L. cv. gina) treated with calcium chloride during storage. Food Science and Technology (Campinas.), 35(2), 266-272. http://dx.doi.org/10.1590/1678457X.6523.

Kim, D.-H., Kim, H.-B., Chung, H.-S., \& Moon, K.-D. (2014). Browning control of fresh-cut lettuce by phytoncide treatment. Food Chemistry, 159, 188-192. http://dx.doi.org/10.1016/j.foodchem.2014.03.040. PMid:24767043.

Kim, T.-H., Böhmer, M., Hu, H., Nishimura, N., \& Schroeder, J. I. (2010). Guard cell signal transduction network: advances in understanding abscisic acid, $\mathrm{CO}_{2}$, and $\mathrm{Ca}^{2+}$ signaling. Annual Review of Plant Biology, 61(1), 561-591. http://dx.doi.org/10.1146/ annurev-arplant-042809-112226. PMid:20192751.

Kollist, H., Nuhkat, M., \& Roelfsema, M. R. G. (2014). Closing gaps: linking elements that control stomatal movement. The New Phytologist, 203(1), 44-62. http://dx.doi.org/10.1111/nph.12832. PMid:24800691.

Kumar, D., Mishra, D. S., Chakraborty, B., \& Kumar, P. (2013). Pericarp browning and quality management of litchi fruit by antioxidants and salicylic acid during ambient storage. Journal of Food Science and Technology, 50(4), 797-802. http://dx.doi.org/10.1007/s13197011-0384-2. PMid:24425984.

Li, Z., Zhao, X., Sandhu, A. K., \& Gu, L. (2010). Effects of exogenous abscisic acid on yield, antioxidant capacities, and phytochemical contents of greenhouse grown lettuces. Journal of Agricultural and Food Chemistry, 58(10), 6503-6509. http://dx.doi.org/10.1021/ jf1006962. PMid:20420437.

Maalekuu, K., Elkind, Y., Tuvia-Alkalai, S., Shalom, Y., \& Fallik, E. (2003). Quality evaluation of three sweet pepper cultivars after prolonged storage. Advances in Horticultural Science, 4, 187-191.
Mahajan, P., Oliveira, F., \& Macedo, I. (2008). Effect of temperature and humidity on the transpiration rate of the whole mushrooms. Journal of Food Engineering, 84(2), 281-288. http://dx.doi.org/10.1016/j. jfoodeng.2007.05.021.

Martín-Diana, A. B., Rico, D., \& Barry-Ryan, C. (2008). Green tea extract as a natural antioxidant to extend the shelf-life of fresh-cut lettuce. Innovative Food Science \& Emerging Technologies, 9(4), 593 603. http://dx.doi.org/10.1016/j.ifset.2008.04.001.

Matile, P., Hortensteiner, S., Thomas, H., \& Krautler, B. (1996). Chlorophyll breakdown in senescent leaves. Plant Physiology, 112(4), 1403-1409. PMid:12226455

Mishra, G., Zhang, W., Deng, F., Zhao, J., \& Wang, X. (2006). A bifurcating pathway directs abscisic acid effects on stomatal closure and opening in Arabidopsis. Science, 312(5771), 264-266. http:// dx.doi.org/10.1126/science.1123769. PMid:16614222.

Philosoph-Hadas, S., Michaeli, R., Reuveni, Y., \& Meir, S. (1996). Benzyladenine pulsing retards leaf yellowing and improves quality of goldenrod (Solidago canadensis) cut flowers. Postharvest Biology and Technology, 9(1), 65-73. http://dx.doi.org/10.1016/09255214(96)00023-3.

Rizzo, V., \& Muratore, G. (2009). Effects of packaging on shelf life of fresh celery. Journal of Food Engineering, 90(1), 124-128. http:// dx.doi.org/10.1016/j.jfoodeng.2008.06.011.

Roelfsema, M. R. G., Staal, M., \& Prins, H. (1998). Blue light-induced apoplastic acidification of Arabidopsis thaliana guard cells: inhibition by ABA is mediated through protein phosphatases. Physiologia Plantarum, 103(4), 466-474. http://dx.doi.org/10.1034/j.13993054.1998.1030404.x.

Song, W., Ma, X., Tan, H., \& Zhou, J. (2011). Abscisic acid enhances resistance to Alternaria solani in tomato seedlings. Plant Physiology and Biochemistry, 49(7), 693-700. http://dx.doi.org/10.1016/j. plaphy.2011.03.018. PMid:21530290.

Sweeney, J., \& Martin, M. (1961). Stability of chlorophyll in vegetables as affected by pH. Food Technology, 15(5), 263.

Torres, A. T. No., Campostrini, E., Oliveira, J. G., \& Bressan-Smith, R. E. (2005). Photosynthetic pigments, nitrogen, chlorophyll a fluorescence and SPAD-502 readings in coffee leaves. Scientia Horticulturae, 104(2), 199-209. http://dx.doi.org/10.1016/j.scienta.2004.08.013.

Wang, Y., Liu, S., Zhang, H., Zhao, Y., Zhao, H., \& Liu, H. (2014). Glycine betaine application in grain filling wheat plants alleviates heat and high light-induced photoinhibition by enhancing the $p s b \mathrm{~A}$ transcription and stomatal conductance. Acta Physiologiae Plantarum, 36(8), 2195-2202. http://dx.doi.org/10.1007/s11738-014-1596-7.

Xanthopoulos, G. T., Athanasiou, A. A., Lentzou, D. I., Boudouvis, A. G., \& Lambrinos, G. P. (2014). Modelling of transpiration rate of grape tomatoes: semi-empirical and analytical approach. Biosystems Engineering, 124, 16-23. http://dx.doi.org/10.1016/j. biosystemseng.2014.06.005.

Zhang, L., Lu, Z., Lu, F., \& Bie, X. (2006). Effect of $\gamma$ irradiation on quality-maintaining of fresh-cut lettuce. Food Control, 17(3), 225228. http://dx.doi.org/10.1016/j.foodcont.2004.10.005. 